Nurettin Akçakale
Abant İzet Baysal University, akcakale_n@ibu.edu.tr, Bolu-Turkey

http://dx.doi.org/10.12739/NWSA.2016.11.3.2A0096

\title{
AYAKKABI TABANLARINDA KAUÇUK KULLANIMI
}

öz

Ayakkabı insan giysilerinin en vazgeçilmezidir. Günümüz koşullarında hemen her ortam için farklı özelliklerde ayakkabı giyilmektedir. Ülkemizde kişi başına 2,7 çift ayakkabı düşmektedir. Ayakkabılar beli başlı iki parçadan meydana gelmektedir. Bunlar saya ve taban kısımlarıdır. Sayalar tekstil, suni deri ve doğal deri türü malzemelerden oluşur. Ayakkabı tabanlarında ise Kösele, PU, EVA, PVC, TPR, Kauçuk, Termo, Neolit vb. pek çok malzeme kullanılmaktadır. Ayakkabılarda kullanılan taban türlerini çalışma ortamı, mevsimsel koşullar vb. göre değişiklik arz eder. Günümüzde ayakkabıya ihtiyaçtan öte moda gözü ile bakıldığından müşterilerin tercihi ve o sezonun trendi taban imalatına yön vermektedir. Taban seçiminde müşterilerin fantezi istekleri, üretime uygun olmaları, ucuzluk, dayanıklılık, bulunma kolaylığı gibi faktörler etkilemektedir. Bu çalışmada ayakkabılarda kauçuk kullanımı, ayakkabı tabanların özellikleri ve taban olarak tercih edilen malzemelerin birbiri ile karşılaştırılması yapılmıştır.

Anahtar Kelimeler: Ayakkabı, Ayakkabı Tabanı, Kauçuk, Taban seçimi, Taban Malzemeleri

\section{THE USE OF RUBBER FOR SHOE SOLE}

\section{ABSTRACT}

Shoe is the most essential human cloth. Today, shoe with different features are worn for almost each different environment. The shoe capitation is 2.7 in our country. Shoe is formed mainly two pieces. These parts are shoe upper and shoe sole. Upper shoe is formed of materials such as textile, artificial leather and genuine leather. In shoe sole many materials such as stout leather, PU, EVA, PVC, TPR, rubber, thermo and neolith are used. The type of sole materials used in shoe changes in accordance with the seasonal circumstances. Today, trend of the season and the preference of the customers lead the production of shoe sole as it is regarded as fashion rather than necessity. Factors such as fantasy demands of customers, convenience for production, reasonable prices, strength and easy access affect the choice of shoe sole. In this study, use of rubber in shoes, properties of shoe sole and the comparison of preferred sole materials with one the other are investigated.

Keywords: Shoe, Shoe Sole, Rubber,

Choice of Sole, Sole Materials 


\section{GİRIŞ (INTRODUCTION)}

Çorap dışında ayağa giyilen her türlü giyecek ayakkabı olarak tanımlanmaktadır. Ayakkabı en önemli insan giyeceklerinden biridir. Ülkemizde kişi başına 2,7 çift ayakkabı düşmekte iken bu oran Avrupa Birliği ülkelerinde ortalama 7 çifttir. Bazı gelişmiş ülkelerde kişi başına 20 çift ayakkabı düşmektedir. Ayakkabı imalinde metal, tekstil, doğal deri, suni deri, elastomer vb çok farklı malzemeler kullanılmaktadır. Ayakkabılar belıi başlı iki ana parçadan oluşur. Bunlar, ayakkabının saya denilen üst kısmı ve yerle temas eden taban kısmıdır. Şekil 1'de bir ayakkabıyı kesitinde ayakkabıyı oluşturan parçaların bazıları görülmektedir. Ayakkabılar daha çok ayağı dış şartlardan koruma amaçlı olarak giyilir [1].

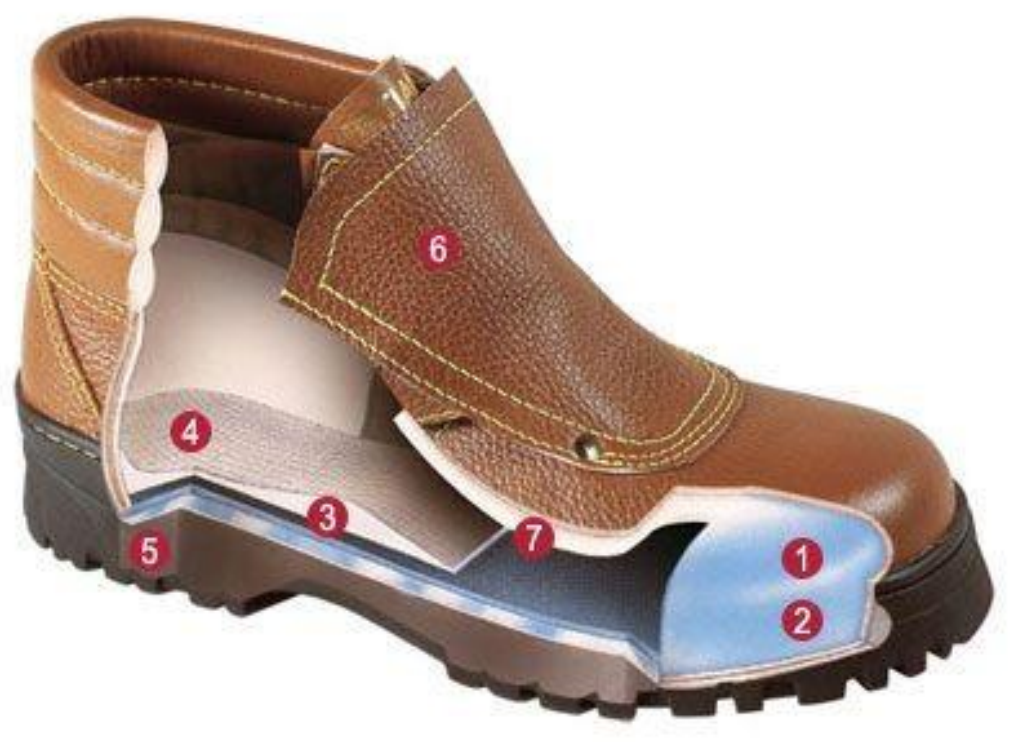

Şekil 1. Ayakkabının belli başlı parçaları; 1. Bombe 2. Yüz 3. Taban astarı 4. Mostra 5. Dış taban 6. Dil ve 7. İ̧̧ astar

(Figure 1. Main parts of shoe; 1. Toepuff 2. Upper 3. Insole 4. Insock 5. Outer sole 6. Tongue and 7. Inner liner)

Ayakkabının altını bir uçtan bir uca örten ve giyildiğinde zemin ile temas eden malzemelere, taban denir [1 ve 2]. Taban malzemeleri, üretildikleri hammadde açısından üç guruba ayrılırlar bunlar; doğal maddeler, sentetik maddeler ve tekstil maddeleridir. Bir ayakkabı tabanı genellikle; iç taban, ara taban ve dış taban olmak üzere üç bölümden oluşur. Bunlarda; iç tabana taban astarı, ara tabana fiyapa denmesine rağmen dış taban doğrudan doğruya taban olarak ifade edilir.

\subsection{Tabanlardan Beklenen Özellikler (Expected Features of Shoe Sole Materials)}

Ayakkabıları kullanım alanlarına göre çok farklı gruplara ayırmak mümkündür. Örneğin pek çok spor dalı bulunmaktadır ve her bir spor dalı için giyilmesi gereken ayakkabının özellikleri farklılık arz etmektedir. Kullanım yerlerine göre ayakkabılarda tercih edilen taban malzemelerinden beklen özellikler dikkate alınarak kullanımları Tablo 1'de görülmektedir [3] . 
Tablo 1. Taban malzemelerinin ayakkabı çeşidine göre dağılımı $[4,5,6$ ve 7]

(Table 1. Distribution of shoe sole materials according to shoe type $[4,5,6$ and 7])

\begin{tabular}{|l|c|c|c|c|c|c|c|c|}
\hline AYAKKABI ÇEŞİDI & PVC & PU & TR & Kauçuk & Kösele & Eva & TPU & Neolit \\
\hline İş Ayakkabıları & $\mathrm{x}$ & & & $\mathrm{x}$ & & & $\mathrm{x}$ & \\
\hline Güvenlik Ayakkabıları & $\mathrm{x}$ & $\mathrm{x}$ & & $\mathrm{x}$ & & & $\mathrm{x}$ & \\
\hline Günlük Ayakkabılar & $\mathrm{x}$ & $\mathrm{x}$ & $\mathrm{x}$ & & & & & $\mathrm{x}$ \\
\hline Kışlık Botlar & & & $\mathrm{x}$ & $\mathrm{x}$ & & & $\mathrm{x}$ & \\
\hline Bayan Ayakkabıları & & $\mathrm{x}$ & $\mathrm{x}$ & & & $\mathrm{x}$ & & $\mathrm{x}$ \\
\hline Mantar Tip Ayakkabılar & & $\mathrm{x}$ & & & & $\mathrm{x}$ & & \\
\hline Özel Spor Ayakkabıları & & & & $\mathrm{x}$ & & & $\mathrm{x}$ & \\
\hline Salon Tipi Ayakkabılar & & & & & $\mathrm{x}$ & & & $\mathrm{x}$ \\
\hline Orta ve Yüksek Kaliteli Ayk. & & & & & $\mathrm{x}$ & & & \\
\hline Spor Ayakkabıları & & $\mathrm{x}$ & $\mathrm{x}$ & & & & & \\
\hline Asker ve Polis Ayakkabıları & & & & $\mathrm{x}$ & & & & \\
\hline Sandaletler & & $\mathrm{x}$ & & & & $\mathrm{x}$ & & \\
\hline Terlikler & & $\mathrm{x}$ & & & & $\mathrm{x}$ & & \\
\hline Kimyasallara Dayanıklı Ayk. & & $\mathrm{x}$ & & $\mathrm{x}$ & & & $\mathrm{x}$ & \\
\hline Ucuz Ayakkabılar & $\mathrm{x}$ & & & & & & & $\mathrm{x}$ \\
\hline Kapalı Tip Ayakkabı & $\mathrm{x}$ & & $\mathrm{x}$ & $\mathrm{x}$ & & & & \\
\hline Kışlık Ayakkabılar & & & $\mathrm{x}$ & $\mathrm{x}$ & & & $\mathrm{x}$ & \\
\hline
\end{tabular}

\section{2. ÇALIŞMANIN ÖNEMI (RESEARCH SIGNIFICATION)}

Ayakkabı tabanlarından beklenen ve istenen bazı özellikler vardır. Bunların başında; tüketici istekleri (fantezi istekler), imalat kolaylığı, tasarım estetiği, montede uygulama kolaylığı, kolay temin edilebilme ve ucuzluk gibi özellikler gelmektedir. Bu özellikler içinde tüketici istekleri (fantezi istekler) birinci sırada yer alır. Tabanlar için temel eğilim dış şartlara karşı dayanıklılık olmalıdır. Tüketici güzel görünen tabanı seçer ve tabanın aşınmasını istemez. Hâlbuki marka güvencesi dışında, görsel olarak tercih edilen tabanın nasıl aşınacağı ve ne kadar dayanıklı olacağı önceden bilinmemektedir [4 ve 5]. Bir taban malzemesinden beklen ortak özellikler şöyle sıralanabilir.

- Dayanıklılık,

- Bükülebilme kabiliyeti (Esneklik),

- Suya karşı direnç,

- Hafiflik,

- Kayma direnci,

- Homojenliktir.

Kuşkusuz ayakkabı tabanının sağlamlığı, yapımında kulıanılan malzemenin cinsine ve kullanılacak ortam şartlarına bağlıdır. Taban beğenisi, modelin türüne göre değişir. Örneğin, fantezi bir ayakkabı tabanı ile bir dağ ayakkabısının tabanı aynı güzellikte olmaz. Giyim esnasında tabanın saya ile aynı sürede eskimesi, günümüz ayakkabıcılığında önemli bir istektir [8 ve 9]. Hafiflik ve rahatlık taban için aranan isteklerdendir. Tüketici hafif ve güzel görünümlü ayakkabı giymeyi ister. Bükülebilirlik, tabandan istenen özelliklerden biridir. Esneme ve yürüme olayı, tabanın bükülmesi ile özdeştir. Bükülmeyen, esnemeyen taban, ayaklara rahatlık vermez. Bükülebilirlik ve esneklik; taban yapımında kullanılan malzemenin cinsine, giyim ortamına (sıcaklık, kimyasal etkili yerler gibi), tabanın kalınlık ve desenine; kullanma yorgunluğu ile ilişkilidir. Kullanıcıdan geri dönen, özürlü ayakkabı sorunlarının başında, taban kırılmaları ve yapışma hataları gelmektedir. Tabandan istenen önemli özelliklerden birisi de kaymazlıktır. Kayan taban, kişiye kaza yaptırıp yaralanmalara sebebiyet verebilir. Halen islak veya kuru ortamlarda 
kaymayı tamamen önleyici bir taban malzemesi bulunmamıştır. Örneğin, gemi personelleri sac zemin üzerinde hareket ettiğinden ve kaymaya müsait bir zemin oluşturduğundan giydiği ayakkabı tabanının, ıslak ortamda kayması hiç istenmez. Ayakkabı tabanı; yerdeki ısıyı (sıcak ve soğuk) ve engebeleri yalıtabilmeli, böyle etkileri ayağa geçirmemelidir. Ayak, ısı ve batma etkilerini duymamalıdır. Elektrikli ortamlarda (yüksek voltajlı) ise, tabanın yalıtım özelliği çok iyi olmalıdır. Ayrıca taban, kullanıldığı ortamlarda kimyasal maddelerden de etkilenmeyip, su geçirmemelidir.

\section{BELLI BAŞLI TABAN MALZEMELERI (COMMONLY USED SHOE SOLE MATERIALS)}

Taban malzemelerini üretildikleri maddelere göre farklı kategorilere göre sınıflandırmak mümkündür. Genel olarak taban malzemeleri doğal ve sentetik taban malzemeler diye iki gruba ayrılır.

\subsection{Doğal Malzemeler (Natural Materials)}

Doğal taban oluşturan esas maddeler kendi aralarında kösele, tekstil taban malzemeleri ve doğal kauçuk olarak üç gruba ayrılır.

\subsubsection{Kösele (Sole Leather)}

Kösele ayakkabı imalatında en eski ve önemli taban maddesidir. Geçmişte üretilen tüm ayakkabıların tabanı köseleden yapılmaktaydı. Ancak 1950'li ylllardan itibaren kösele yerini sentetik taban malzemelerine bırakmaya başlamıştır. Kösele, büyük baş hayvan ham derilerinin tabaklanmasıyla elde edilen 2,5-10,0 mm kalınlığında sert, yoğun yapılı mamul deridir. Köselenin de boyun, etek, bacak, sırt bölümleri vardır. Köselelerin en değerli ve dayanıklı kısmı sırttır. Günümüzde kösele kaliteli, fantezi ayakkabıların ve terliklerin tabanlarında kullanılmaktadır. Kösele balyalar halinde bağlanmış olarak kilo ile satılır. Bir balya kösele kalınlığına bağlı olarak 50 ile $100 \mathrm{~kg}$ kadardır. Bayan (Zenne) ayakkabılarda ve terliklerde ince kösele kullanılırken merdane ayakkabılarda kalın kösele tercih edilir.

\subsubsection{Doğal Kauçuk (NR) (Natural Rubber)}

Doğal kauçuk, ilk defa Latince ismi kaynağı Heveabrasiliensis olan bir tür ağacın gövdesinden elde edilmiştir. Apocyanacea ve Euhorbiocea familyasından tropikal bitkilerin kabuklarında yapılan yarıklardan akan ve lateks ismi verilen özsuyunun asitler, $1 s ı$ vb yollarla pıhtılaştırılması suretiyle oluşur. Lateks, ağaç kabuğunun özel bıçakla çizilip özel kapta toplanması ile elde edilir. Çizilen ağaç normal şartlarda 4 saat kadar lateks akıtır. Toplanan latekse koruyucu katılarak akışkan kalması sağlanır. Üretimin o80'lik kısmı bu latekstir. 20 kadarı ise ertesi güne kadar akar ve pıhtılaşır. Günümüzde birçok doğal kauçuk türleri vardır [10 ve 11]. Şekil 2'de çizilmiş olan kauçuk ağacından lateks akıtılması işlemi görülmektedir. 


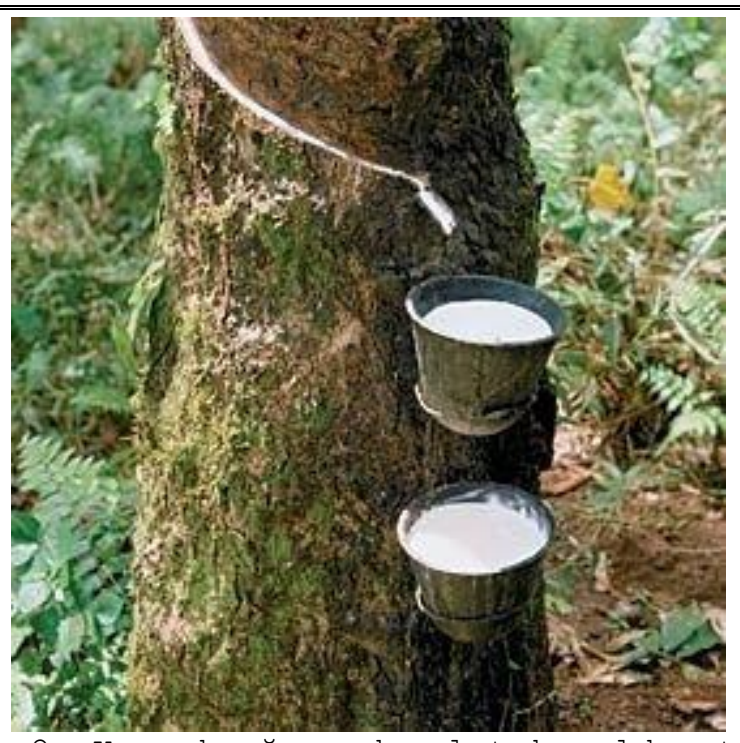

Şekil 2. Kauçuk ağacından lateks elde etmek (Figure 2. Extracting latex from rubber tree)

\subsubsection{Tekstil Esaslı Taban Malzemeleri \\ (Textile Based Sole Materials)}

Tekstil taban esas maddesi jüttür. Jüt yüksekliği 2-4 metreyi bulan başlıca Hindistan'da yetişen sıcak ve rutubetli iklim isteyen yıllık bir bitkidir. Köklerine yakın yerlerden kesilen bitki, yaprak ve tohumlarından ayrıldıktan sonra ketende olduğu gibi işlenir. Jüt kesildiği zaman beyaz veya hafif renklidir. Zamanla hava, güneş ve rutubetin etkisi altında koyu bir renk alır. Renkler kaliteyi etkiler. Jütün normal nem oranı $\frac{\circ}{13}, 75^{\prime}$ dir. Kuru yerlerde $\frac{0}{7}$ olan nem oranı rutubetli yerlerde $\% 24^{\prime}$ e kadar çıkabilir. Jüt çoğunlukla çuval, kanaviçe gibi maddelerin yapımında kullanılır. Jüt, kauçuk ya da plastik maddeler ile birlikte hazır taban yapılarak taban montajında kullanılır. Bu tür tabanlar espadril olarak isimlendirilen yaz türü hafif ayakkabıların tabanlarında kullanılır. Jüt tabanların yapımında, dokunmuş haldeki jüt alüminyum taban kalıplarına uygun biçimde kesilir. Kalıba yerleştirilen jütün üstüne kauçuk ya da plastik enjekte edilerek hazır taban oluşturulur.

\subsection{Sentetik Taban Malzemeleri (Synthetic Sole Materials)}

Taban yapımında kullanılan belli başlı sentetik maddeler, neolit, suni kauçuklar, PVC, EVA, PU (poliüretan) ve termoplastiklerdir. Sentetik maddelerin ayakkabı tabanında kullanılışı üç şekilde olur [12]. Sentetik taban malzemeleri plaka halindedir. Kauçuk ve neolit gibi. Ayakkabı üreten işletmede bu malzemeye tabanın şekli verilir. Sentetik maddeye taban şekli verilmiştir. Örneğin; PVC ve termoplastik hazır tabanlar. Granül haldeki sentetik madde (PVC ya da termoplastik), ipli monte veya atom monte yöntemleri ile enjeksiyon makinesindeki alüminyum kalıba takılı sayanın tabanına enjekte edilerek taban oluşturulur. Taban yapımında kullanılan sentetik malzemeleri kauçuk dışı sentetik malzemeler ve de sentetik kauçuk taban malzemeleri diye gruplandırabilinir.

\subsubsection{Taban Yapımında Kullanılan Sentetik Kauçuklar (Synthetic Rubbers Used in the Shoe Sole)}

Doğal kauçuğun elde edilmesi ve işlenmesi çok pahalı olduğundan ve üretilen miktar talebi karşılayamadığından, araştırmacılar bu maddenin benzerini yapmaya zorlanmıştır. Tabanlar her ne kadar kauçuk, 
PVC, poliüretan olarak anllsalar da mekaniksel özelliklerini iyileştirmek için ve maliyeti düşürmek için dolgular kullanılır. Kauçuk tabanlar bir kauçuk çeşidinden oluşabileceği gibi birden çok kauçuğun bir araya gelmesi ile de üretilebilir [12]. Ayakkabı taban imalinde tek başına ya da başka bir kauçukla beraber kullanılan belli başlı sentetik kauçuk çeşitleri şunlardır;

- BR : Butadien Kauçuklar

- SBR: Stiren-Butadien Kauçuklar

- IR : İsopren Kauçuklar

- IIR: Butil Kauçuklar

- NBR: Akrilonitril-Butadien Kauçuğu

- AU : Poliüretan Kauçuklar

- TPE: Termoplastikelastomerler

- SBS: Stiren Butadien Stiren Kauçuklar (Termokauçuklar)

\subsection{Kauçuk Dışı Sentetik Taban Malzemeleri (Synthetic Sole Materials Except Rubber) \\ 3.3.1. Neolit (Neolith)}

Neolit; kauçuğun aktif olmayan dolgularla yüksek oranda karıştırılması ile elde edilir. Ayakkabı taban üreticilerinin "suni kösele" olarak ta isimlendirdikleri neolit köpüklü bir maddedir. Plaka halinde üretilir. Kuvvetli kompaksiyon preslerde levha haline getirilir. Sertliği 90-95 shore A dır. Suni köseleler çeşitli kalınlıklarda ve doğal kösele renginde üretilmektedir. Son yıllarda kahverengi neolitler de piyasaya çıkarılmıştır. Düşük kaliteli ayakkabılar ile parmak arası sandalet ayakkabılarda tüketilir.

\subsubsection{Polivinil Klorür (PVC) (Polyvinyl Chloride)}

Ayakkabı endüstrisinde PVC termoplastik formunda kullanılır. Kömür veya petrolden gelen vinilkloridmonomer gazının polimerizasyonu ile elde edilir. Bu polimer sert, reçineli, renksiz, $170-180^{\circ} \mathrm{C}^{\prime} \mathrm{de}$ eriyen katı bir maddedir. Ayakkabı endüstrisi için kullanılabilir, esnek, ısıya dayanıklı bir malzeme olabilmesi için diğer malzemelerle bileşim haline getirilmesi gerekmektedir. PVC polimer reçinesi kalıplanma sıcaklığında ısıtıldığında göreceli olarak kararsız bir yapıya sahiptir. PVC, işleme esnasında zararlı bir madde olan HCl salgılamaktadır. Bu nedenle ortamın havalandırılmasına dikkat edilmelidir [13 ve 14]. Bileşimde esneme ve kararlılığa yardımcı olmak ve sonraki aşama olan kalıplama operasyonunu kolaylaştırmak için proses yardımcıları ve yağlayıcı maddeler ilave edilir. Eğer hücresel bir ürün isteniyorsa uçurucu maddeler kapsayabilir ve bazen bu farklı özelliği vermek üzere Nitril kauçuk veya poliüretan gibi polimerler ilave edilir. Esnekliği elde etmek üzere plastikleştiriciler ilave edilmelidir.

Plastikleştiriciler, berrak, hızlı bir şekilde buharlaşmayan yüksek kaynama noktasına sahip renksiz sıvılardır ve PVC tarafından absorbe edilir. PVC polimer zincirleri arasında yağlayıcı madde gibi rol oynarlar, birbirleri üzerinde kayarak malzemenin esneme ve bükülmesine olanak sağlarlar [15]. Stabilizörler, malzemenin bozulmasını durduran ve PVC ile bileşimi hazırlandığında, işlendiğinde ve kalıplandığında hidroklorikasit (HC1) veren hem sıvı hem de katı halde bulunabilen kimyasallardır. Son proses hazır tabanları (ayakkabı tabanına direkt kalıplama) oluşturmak için granül haldeki PVC polimeri karıştırılır. Bu proses basit olarak granülleri eritir ve sıcak eriyik PVC'yi istenen kalıba geçirir. Kalıptaki malzemeler soğur, katılaşır ve erimeksizin kalıcı olarak kalıbın şeklini alır. Ayakkabı sanayinde termoplastik kauçuk tabanların kullanıldığı ayakkabılarda PVC'den 
üretilmiş tabanlar da kullanılabilir. PVC tabanlar sert, dolayısıyla çabuk aşındığı, kırıldığı için düşük kaliteli malzemedir. Ucuz ve düşük kaliteli ayakkabılarda tercih edilir.

\subsubsection{Poliüretan (PU) (Poliurethane)}

Poliüretan taban malzemeleri "Reaksiyon Kalıplama" olarak adlandırılan kalıplama prosesi ile şekillenir. Bu bir çeşit polimerizasyon prosesi, bileşim ve kalıplama prosesidir. Poliüretan bir taban gerekli kimyasal içeriğin sıvı formda (veya ısı ile sıvı hale getirilen formda) bir karıştırma odasının içerisine gönderilmesi, karıştırılması ve bir kalıp içerisine transferi ile yapılır. Poliüretan karışımı henüz kalıp içerisinde iken sıvı bir poliüretan oluşturmak için reaksiyona girer. Reaksiyon süresince gaz üretilir ve bu gaz oluşumu varsayılan hücresel yapıya sahip poliüretanı oluşturur [16]. Poliüretan taban malzemesinin temel kimyasal içeriği bir polihidroksil bileşiği ve biride izosiyanattır. Bu iki kimyasal birlikte reaksiyona girerler ve polimer zincir yapısını oluştururlar. Çapraz bağ yapıcı maddeler, katalizörler (kauçukta kullanılan hızlandırıcılar gibi), silikon, bir uçurucu madde ve gerekli ise pigment ilave maddelerdir [17].

Bu temel maddelerin tamamı yüksek derecede reaktif maddelerdir ve reaksiyon ve kalıplama dikkatli bir şekilde kontrol edilmelidir. Çalışabilir bir sistem için kimyasal tedarikçi bu kimyasalları yönetilebilir formda üretir. İki sıvı kimyasal bunların birbirleri ile kombine edilmesi ile hazırlanır. Böylelikle kimyasallar nakliyat ve depo şartlarında kararlı bir şekilde kalır. Tabanları üretmek için iki kimyasal birbirleri ile karıştırılır ve doğru oranlarda enjekte edilir veya kalıp içerisine dökülür. Ölçüm, karıştırma ve kalıplama makinesinin içerisinde yapılır. Bu iki kimyasal reçine ve sertleştirici olarak adlandırılır [18]. Poliüretan reaksiyon kalıplama prosesinde polihidroksil bileşiğinin tipi temel kimyasal belkemiği ve kullanımda ve prosesin belirlediği sonuç poliüretanın hücresel yapışım oluşturur. İki temel polihidroksil bileşiği poliester ve polieterdir [19]. Köpüklü, hafif tabanların üretiminde kullanılır. Kalın, tank ökçeli terlik ve sandalet tabanlarında poliüretan tercih edilir. Hafif olmaları, iyi aşınma direnci, iyi esneme direnci poliüretan tabanların diğer taban malzemelerine göre üstünlükleridir [20 ve 21].

\subsubsection{Etilen Vinil Asetat (EVA) (Ethylene Vinyl Acetate)}

$\mathrm{Bu}$ malzeme etilen ve vinil asetatın kopolimerizasyonu ile üretilir. Taban için hem termoplastik hem de çapraz bağlanmış formda kullanılır. Kopolimerin vinil asetat kısmı polietilenden daha yumuşak ve daha kauçuğumsudur. EVA, dayanıklılığa, esnekliğe ve hafifliğe sahip olan ve PVC için kullanılan kalıplama yöntemi ile aynı şekilde kalıplanan bir taban malzemesidir. Buna rağmen, EVA vulkanize kauçuk gibi çapraz bağlanabilir, bileşik halinde genişletilebilir, işlenebilir ve kalıplanabilir. Doğal ve sentetik kauçuktan daha pahalı olduğu için, EVA'nın pişmiş formu yalnızca mikro hücreli malzeme olarak üretilir. Başlangıçtaki düşük yoğunluğu, işleme ve kalıplama kolaylığı, görünüm ve tutum özellikleri ham EVA polimerinin başlangıçtaki yüksek fiyatını karşılayabilir [22]. Katı formundaki gibi, hücreli yapıda sunulan termoplastik çeşidi dikkate değer bir şekilde karışıklığa neden olmaktadır. Ayakkabı üretimi için, çapraz bağlı mikro hücreli çeşidi yalnızca tabaka veya hazır taban şeklindedir. Termoplastik çeşidi granül veya kalıplanmış taban olarak üretilebilir. Böylelikle karışıklık yaşanmaz. Başlangıçta, katı termoplastik EVA ve PVC'ye rakip olmuştur. Çünkü EVA düşük sıcaklıklarda esneme özelliklerine sahiptir. Bununla birlikte, yakın 
zamandaki deneyimler, EVA'nın PVC'de olduğu gibi uygulama çeşitliliği eksikliğine neden olduğunu göstermiştir. Ayrıca aşınma direnci zayıftır. Plaj terliği imalatında kullanılır. Gözenekli yapısından dolayı su emmesi bir dezavantajdır.

\subsubsection{Polistiren (Polystyrene)}

Polistiren, moda olan sert, katı dişli tabanlar dışında kullanılmaz. HEPS, bütün tabanı kaplamak için kullanılabilir. Bununla birlikte ince bir taban ve ökçe kapağı tutturulur. Bel bölgesinde kırılma hatası meydana gelebilir. Katı tabanlar için polipropilen, ABS, katı poliüretan ve tahta kullanılır [23].

\subsubsection{Polietilen (Polyethylene)}

Taban malzemesi olarak kullanılmamasına rağmen polietilenin büyük çoğunluğu düşük yoğunluktadır ve ekonomik olmasından dolayı ayakkabıcılıkta iki farklı alanda kullanılır. Bu alanların ilki ökçe kapağı yapıdır. Kösele ve deri plakanın yerini alan tek parça polietilen kalıplama orijinal olarak bu amaç için kullanılır. Ayrıca ökçe dolguları kalıplanmış birimler ve taban kalıplama türleri için malzemenin kullanımım azaltmak için kullanılır. Ökçe alanını desteklemek, bozulmaya engel olmak için faydalıdır.

\subsubsection{Polipropilen ve Monomer Reçineler (Polypropylene and Momomer Resins)}

$\mathrm{Bu}$ tip malzemeler çok sert ve katı olduğu için taban malzemesi olarak yaygın bir şekilde kullanılmaz. Bununla birlikte bu malzemeler bayan ökçe ve ökçe kapaklarında kullanılır. Diğer kullanım alanları futbol, basketbol ve kayak botları spor ayakkabı tabanlarıdır [24].

\section{AYAKKABI TABANLARINDA KAUÇUK KULLANIMI (THE USE OF RUBBER FOR (IN) SHOE SOLE)}

Doğal ve yapay kauçuklar kendilerine has üstün özellikleri nedeni ile geniş bir kullanım alanına sahiptirler ve endüstrinin pek çok alanında kullanılırlar. Bu malzemelerden üretilecek ürünün gerektirdiği özelliklere sahip olabilmesi için işlenme sırasında çok sayıda ve değişik niteliğe sahip katkı ve dolgu maddeleri katılır. Kauçukların dış şartlara karşı fiziksel, kimyasal ve mekanik özellikleri artırıcı ve maliyeti düşürücü olarak katkı ve dolgu maddeleri önemli ölçüde bulunur. Günümüzde kauçuk malzeme üretiminde pek çok anorganik ve mineral özellikli madde dolgu malzemesi olarak kullanılmaktadır. Kauçukların kullanım alanlarından biride ayakkabıcılık sektörüdür. Geçen 50 yılıık bir süre içinde, ayakkabı üretiminde ve ayakkabı imalatında kullanılan malzemeler içerisinde en fazla gelişme, dış taban malzemelerinde olmuştur. Son yıllara kadar kösele, ayakkabılarda taban olarak kullanılan en yaygın doğal ve yegâne malzeme iken günümüzde ise kullanımı azalmış olup, 2005 yılı verilerine göre köselenin taban olarak kullanımı ayakkabı üretimi içindeki oranı ancak $\frac{\circ}{5}, 9^{\prime}$ dur. Günümüzde ayakkabı tabanları çoğunlukla sentetik malzemelerden ve kauçuk esaslı malzemelerden yapılmaktadır. Taban imalatında sentetik malzemelerin kullanımının artışı daha çok ekonomik bir olaydır. 


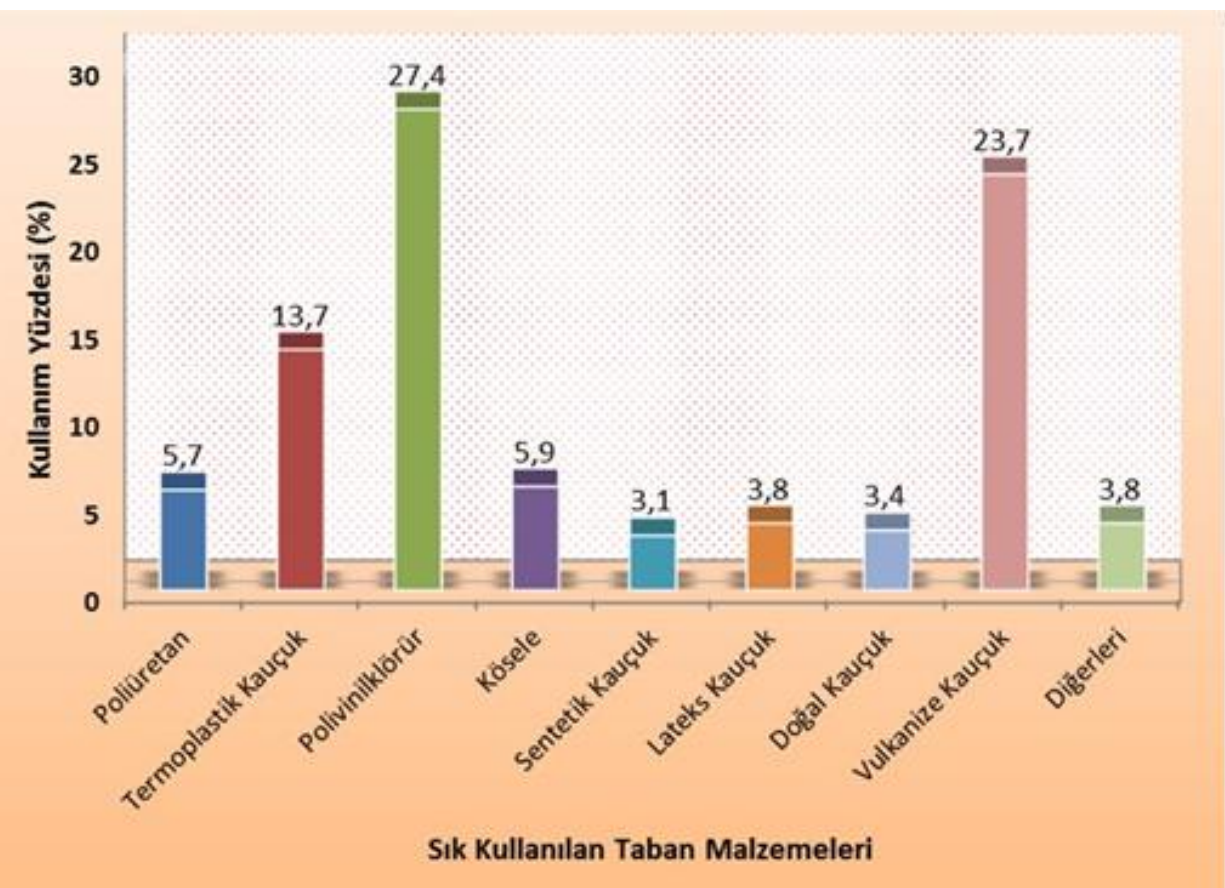

Şekil 3. Ayakkabılarda kullanılan en yaygın taban malzemelerinin kullanım yüzdeleri [14 ve 24]

(Figure 3. Using percentage of commonly used shoe sole materials [14 and 24])

Hazır taban yapımı geliştikçe, topuk (ökçeyi) de kapsayan bir yapım şekline dönüşmüştür. Bu şekilde, ökçeli tabanlar, ayakkabı üretimini ucuzlatmakta ve böylece tabanlar sayaya kolay monte edilebilmektedir [14 ve 24]. Günümüzde; müşteri istekleri, fiyat ve malzemelerin gelişimi gibi etkenler göz önünde bulundurularak kullanım yeri ve amacına göre çok farklı malzemeler taban imalatında kullanılmaktadır. Taban malzemelerinin yaklaşık olarak kullanım oranları Şekil 3'te görülmektedir. Kullanım oranları incelendiğinde de görüleceği gibi kauçuk grubu en fazla kullanılan grubu teşkil etmektedir.

\subsection{Kauçuk Esaslı Ayakkabı Tabanlarının Mekaniksel Özellikleri (Mechanical Properties of Rubber Based Shoe Sole Materials)}

Ayakkabı tabanlarında; kullanım yeri şartlarına göre farklı doğal ve sentetik malzemeler kullanılmaktadır. Taban malzemelerin kullanım oranları arasında kauçuk esaslı malzemelerinin oranı yaklaşık ○34 dür [14 ve 24]. Kauçuk esaslı taban malzemelerinin diğer taban malzemelerine göre yağlara, ısıya ve kimyasallara karşı aşınma ve deformasyon dayanımları iyidir. Elektrik geçirgenliği özelliğinden dolayı statik elektriği vücuttan atmaya elverişli, kaymazlık özelliğine sahiptir. 200 ile 250 'C sıcak ortamlara dayanıklıdır. İlave katkllar ile anti statiklik özelliği verilebilir. Özellikle iş ve günlük ayakkabılarda, botlarda ve kışlık ayakkabılarda elastomer esaslı kauçuk tabanların yoğun olarak kullanılması ve ayakkabı tüketimindeki artış bu çalışmanın ortaya çıkmasında önemli rol oynamıştır. 
Tablo 2. Elastomer esaslı ayakkabı topukları ve tabaklar için istenilen standart özelikler

(Table 2. Standard properties for elastomer based heels and layers)

\begin{tabular}{|c|c|c|c|}
\hline Özellikler & Referans & $\begin{array}{c}\text { Tip } 1 \\
\text { (Frezeli Tabanlar) } \\
\text { Kabul Kriterleri }\end{array}$ & $\begin{array}{c}\text { Tip } 2 \\
\text { (Havuzlu Tabanlar) } \\
\text { Kabul Kriterleri }\end{array}$ \\
\hline Yoğunluk $(\mathrm{g} / \mathrm{cm} 3) \quad$ TS 2827 & TS 5499 & Max. 1,35 & Max. 1,50 \\
\hline $\begin{array}{l}\text { Sertlik (Shore A) } \\
\text { TS 1324-2875 DIN } 53519\end{array}$ & TS 5499 & Min. 70 & Min. 55 \\
\hline $\begin{array}{l}\text { Aşınma Miktarı }(\mathrm{mm} 3) \\
\text { TS EN } 12770 \text { DIN } 53516 \\
\text { ISO } 4649\end{array}$ & TS 5499 & Max. 200 & Max. 250 \\
\hline $\begin{array}{l}\text { Kopma Dayanımı (MPa) } \\
\text { TS EN ISO } 12803 \text { DIN } 53504\end{array}$ & TS 5499 & Min. 5,88 & $\operatorname{Min} .5,88$ \\
\hline $\begin{array}{l}\text { \% Uzama Miktarı }(\mathrm{mm}) \\
\text { TS EN ISO } 12803 \text { DIN } 53504\end{array}$ & TS 5499 & Min. 175 & Min. $\div 200$ \\
\hline $\begin{array}{l}\text { Esnetme Dayanımı (Adım) } \\
\text { TS EN ISO } 20344 \text { DIN } 53543 \\
\text { SATRA TM } 161\end{array}$ & TS 5499 & Min. 30000 & Min. 30000 \\
\hline $\begin{array}{l}\text { Yırtılma Dayanımı }(\mathrm{kg} / \mathrm{mm}) \\
\text { TS 4698- TS EN } 12771 \text { DIN } \\
53507\end{array}$ & & Min. $8 \mathrm{~kg} / \mathrm{mm}$ & Min. $6 \mathrm{~kg} / \mathrm{mm}$ \\
\hline
\end{tabular}

Ayakkabı tabanlarına gerek mekaniksel özelliklerini artırıcı gerekse maliyeti azaltmak maksatlı ve proses işlemlerini kolaylaştırmak için dolgu malzemeleri kullanılmaktadır. Hazır kauçuk tabanlarda olması gereken mekaniksel özellikler TS 5499, TS 4698 ve TS 5501 de verilmiştir. Tablo 2'de TS 5499 ye göre elastomer esaslı ayakkabı topukları ve tabanlar için istenilen özellik değerleri verilmiştir. Hazır kauçuk tabanlar tip 1 ve tip 2 diye iki grupta incelenmektedir. Üretim bakımından aralarında bir fark bulunmamaktadır.

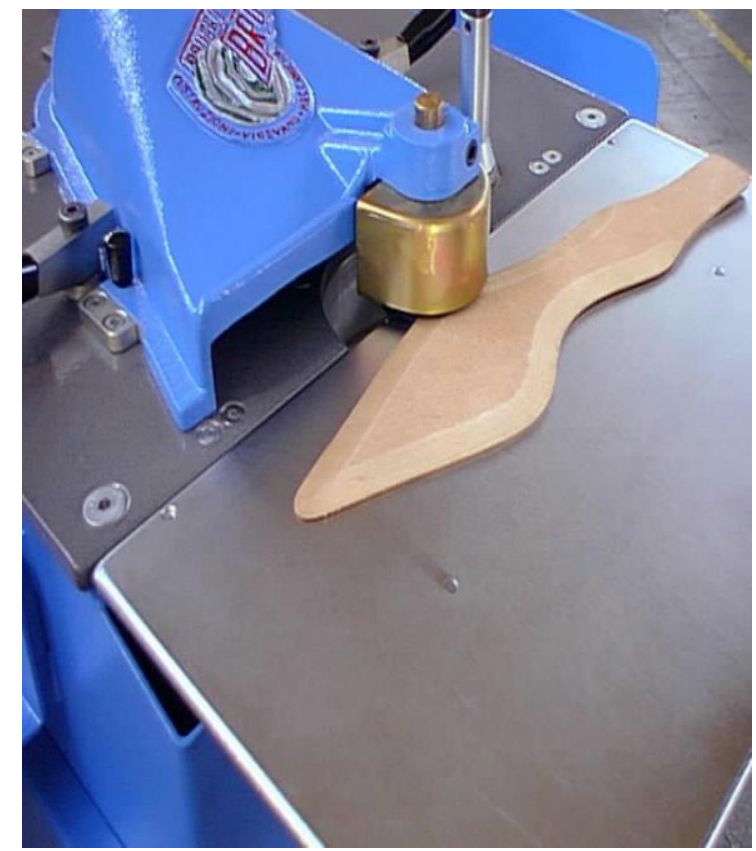

a. Yarı İşlenmiş frezeli taban (Semi finished shoe sole)

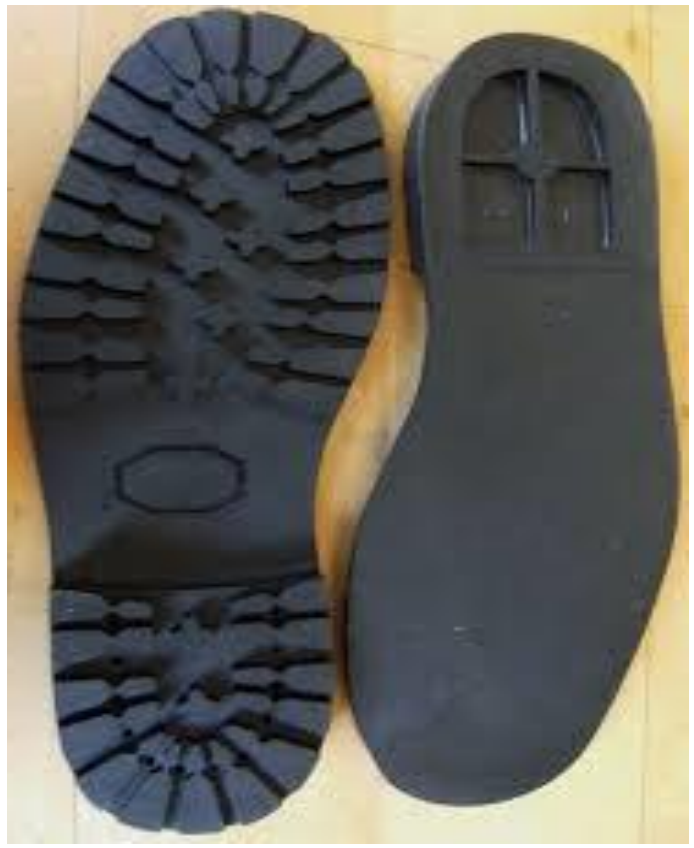

b. Hazır havuzlu taban (Ready shoe sole) Şekil 4. Elastomer esaslı hazır tabanlar (Figure 4. Elastomer based shoe sole) 
Tip 1 elastomer malzemeler sert ve frezede işlemeye uygun özellikte olmalıdır. Taban malzemesi üretildikten sonra dış kenarları ya da taban iç yüzeyine freze tezgâhlarında tıraşlama işlemleri yapılır. Sertlik değerleri en az 70 Shore A olmalıdır. Sertlik değerinin bu değerin altında olması durumunda frezede ve diğer tezgâhlarda işlenemez. Neolit, kösele, PVC gibi taban malzemelerinin sertlik değeri 70 Shore $A^{\prime} n ı n$ üzerindedir. Tip 2 olarak isimlendirilen kauçuklar ise hazır havuzlu taban olarak isimlendirilir. Tip 1'e göre daha yumuşak malzemelerdir. Hiçbir işlem yapılmadan direk ayakkabıya monte edilir. Her iki malzeme grubu arasında mekaniksel özellikler arasında farklılıklar bulunmaktadır. Şekil 4 a'da havuzlu taban olarak isimlendirilen kauçuk esaslı hazır ayakkabı tabanı görülmektedir. Şekil 4 b'de frezeli üretime uygun ayakkabı tabanı ve ökçe (topuk) lastiği parçası görülmektedir.

\section{SONUÇ (CONCLUSION)}

İnsanlar var oldukça ayakkabı giymek zorundadırlar. 2015 rakamları ile Türkiye nüfusunun 78741053 kişi olduğu ve hangi yaşta olursa olsun bu insanların ayakkabı ihtiyacı düşünüldüğünde taban konusu üzerinde akademik olarak ciddi çalışılması gereken bir alandır. Türkiye 188 milyon çift ile dünyanın ihracat sıralamasında 11. Sıradadır. Avrupa Birliği yaklaşık 3,1 milyar çift yaklaşık 50 milyar Euro değerindeki ayakkabı tüketimiyle bu alanda dünyada birinci sıradadır. Amerika Birleşik Devletleri ise 2,3 Milyar çift ayakkabı tüketimi ile bu sektördeki en büyük ithalatçı ülke konumundadır [25 ve 26]. Belli bir üretim kalite politikasına sahip işletmeler yada spesifik özelliklere sahip ayakkabı tabanı üreticilerinin bazıları ulusal ve uluslararasi standartlarda belirlenen değerlerle yetinmeyip işletme kalite politikasına göre şartnamelerde istenilen özelliklere göre ileri test kriterlerini baz almaktadırlar. Ülkemizde taban üretiminde belli bir kontrol ve denetim mekanizmasının olmamasi nedeni ile üretilen tabanın özeliğini bilen ya da üretilen tabanın kullanım koşullarını bilen işletme sayısı oldukça azdır. Kurumsal işletmelerin haricinde hemen hemen hiç bir taban fabrikasında test laboratuvarı yoktur ve üretilen tabanların özellikleri hakkında işletme yetkilileri bilimsel bir bilgiye sahip değildir. Ülkemizde ayakkabı taban üretiminde dış ülkelere ihracat yapan büyük firmalar ve şartname ile ayakkabı ya da taban alan Milli Savunma Bakanlığı, İçişleri Bakanlığı, İş güvenliği ayakkabıları gibi yerlere satış yapanlar dışından belıi bir kalite politikası yoktur [8 ve 25].

\section{KAYNAKLAR (REFERENCES)}

1. Türk Standartları Enstitüsü, (1988). TS 5550, Ayakkabılar, Necatibey Caddesi No:112 Bakanlıklar, Ankara.

2. Akçakale, N., (2008). NR/SBR Tipi Elastomer Esaslı Ayakkabı Taban Malzemelerinin Mekaniksel Özelliklerine Bazı Dolgu Maddelerinin Etkilerinin Incelenmesi. Doktora Tezi. Sakarya Üniversitesi Fen Bilimleri Enstitüsü, Sakarya.

3. Akcakale, N., Demirer, A., Nart, E., and Ozsert. I., (2010). Effects of Glassspheres on the Mechanical Characteristics of NRSBR Type Elastomers. Scientific Researchand Essays. Vol:5(8), pp:758-762, 18 April, wWw.academicjournals.org/SRE ISSN 19922248 (c) 2010 Academic Journals.

4. Türk Standartları Enstitüsü, (1988). TS 5548, PVC'den Ayakkabı Tabanları ve Topukları, Ayakkabılar. Necatibey Caddesi No:112 Bakanlıklar, Ankara.

5. SATRA, (1994). Adhesionand Soling Testing, Modern Shoemaking, Satra Footwear Technology Center. Number:44, November, London. 
6. Balkır, G., (2014). Kişisel Görüşme, İstanbul.

7. Şenöz, D., (2014). Kişisel Görüşme, İstanbul,

8. Usta, A., (2013). Kişisel Görüşme, Balay Kauçuk, Topkapı, İstanbul.

9. Akgüneş, A., (2013). Kişisel Görüşme, İstanbul.

10. SATRA, (1995). Moulding on Soling, Modern Shoemaking, Satra Footwear Technology Center. Number:53, London.

11. SATRA, (1995). Footwaer Open Tech, Material Testing, Satra Footwear Technology Center, Number:53, London.

12. İstanbul Kauçuk Derneği, (1998). Kauçuk ve Elastomer Teknolojisi, Kauçuk Derneği Seminer Notları, İstanbul.

13. Babbit, O.R., (1978). The Vanderbilt Rubber Handbook, Vnaderbilt CompanyInc. 30 Wifield Street, Norwalk, C.T., USA.

14. SATRA, (1993). Testingfor Quality, Modern Shoemaking, Satra Footwear Technology Center, Number 39, London.

15. Kuyulu, A., (2002). Polimerlerin İşlenmesi, Yıldız Teknik Üniversitesi Ders Notları, İstanbul.

16. TMMOB Kimya Mühendisleri Odası, (1989). Plastik İşleme Teknikleri ve Kalite Kontrol.

17. Kapur, N., (2001). Polyurethane Soling Technology, London.

18. Dunbrook, F.R., (1996). Cemistry Organic, Fluorocarbons, Plastic, Silicons, Rubber Vol:20, P.F. Collier, A Division of Newfield Publications, Inc.

19. Coulson, S.H., (1989). Rubber Technology, Esso Research, S.A., Diegemen, Beligum.

20. Karataş, A., (20019. Elastomer Malzemelerin Statik ve Dinamik Özellikleri. İstanbul Teknik Üniversitesi Fen Bilimleri Enstitüsü, Yüksek Lisans Tezi, İstanbul.

21. Andrew, G.D. and Tobias, J.D., (1988). Additives for Improved Processing of Microcellular Polyurethane, Annual Technical Marketing Conferance.

22. Qenos Chemistry Resource, (2001). Production of BR-Polybutadiene Rubber, December.

23. Prat, R., (1993). Plasticand Rubber-Industry Overview. International Institute of Synthetic Rubber Producers, Houston.

24. Akçakale, N. ve Koç, Y., (2005). PVC Ayakkabı Tabanları, Plastik ve Ambalaj Teknolojisi, İstanbul, Mayıs.

25. T.C. Doğu Akdeniz Kalkınma Ajansı, (2014). Ayakkabıcılık Sektör Raporu.

26. Orica Limited, (1992). Polyurethane, Chemical Fact Sheet, November. 